\title{
Experimental studies on some genetic effects of marine pollution
}

\author{
B. Battagliai, ${ }^{1}$, P. M. Bisol ${ }^{1}$ \& E. Rodinò ${ }^{1}$ \\ ${ }^{1}$ Institute of Animal Biology, University of Padua, 10 Via Loredan; I-35100 Padua, Italy, \\ and \\ ${ }^{2}$ Institute of Marine Biology, C. N. R.; I-30122 Venice, Italy
}

\begin{abstract}
Following the results of a series of investigations carried out to estimate the degree of marine pollution by utilizing certain marine filter feeders, such as the blue mussel Mytilus galloprovincialis, research has been planned to detect possible genetic effects of pollutants, with special attention to those acting at the population level. The possible selective role of pollutants has been studied both in natural (Mytilus) and in experimental (Tisbe holothuriae) populations by utilizing some electrophoretically-detected gene-enzyme systems as genetic markers. For some of the seven polymorphic loci studied in Mytilus (AP, LAP, 6-PGD, $\mathrm{IDH}_{\mathrm{s}} \mathrm{IDH}_{\mathrm{m}}, \mathrm{PGI}, \mathrm{PGM}$ ) significant changes in gene frequencies have been detected which can be related to the degree of pollution in the sampling areas. In the more polluted areas these changes were accompanied by a decrease in the frequency of heterozygotes. Similar changes in gene frequencies also occurred in laboratory populations of the copepod Tisbe, reared under various experimental conditions. In particular, certain alleles of two loci, PGI-l and AP-1, exhibited an increase in frequency, especially in populations cultured at various levels of oil pollution. This trend appeared more significant for the locus PGI. The fact that equilibria are reached and that the less favoured alleles are nevertheless maintained in the populations, even at extremely low frequencies, suggests the balanced nature of these enzyme polymorphisms. The significance of the above findings is briefly discussed.
\end{abstract}

\section{INTRODUCTION}

In the last two decades, considerable effort has been devoted to studying the effects of pollutants on marine life. The diverse effects detected concern different levels of organization, from the organismic to the community level. They include, for instance, modifications in life cycle, physiology, behaviour, population dynamics, or community structure (see Ruivo, 1972).

However, very little attention has thus far been given to those more subtle alterations which may occur at the level of the genetic material. The scantiness of information on the genetic effects of pollution is mainly due to the fact that until recently even the formal genetics of marine organisms was little known. In this respect, the application of electrophoretic techniques has proved a most valuable tool for investigations on gene pools, and has made it possible to detect and analyse changes, including those evoked by environmental pollution, in the genetic make up of marine individuals and populations. Such an approach requires (a) knowledge of the quality and quantity of pollutants in a determined area, especially of mutagenic agents, and (b) thorough information on the ecology and life-cycle characteristics of the species concerned. 
In the last few years, an extensive programme on monitoring pollution in the Lagoon of Venice has been developed using the blue mussel Mytilus galloprovincialis as indicator. This active filter-feeder proved especially useful for monitoring hydrocarbon pollution (Fossato \& Siviero, 1974), and it appears a promising tool for the evaluation of other pollutants. With this background information, our research aims at detecting possible genetic effects of pollutants, including their carcinogenic, mutagenic and/or selective action.

The possible selective role of pollutants has also been investigated experimentally, by utilizing laboratory populations of the marine copepod Tisbe holothuriae. For both species some electrophoretically-detected gene-enzyme systems have been used as genetic markers. The first results were reported in a previous paper (Battaglia et al., 1979). The present work provides additional information on the subject and a set of new data useful for a better understanding of some of the former results.

\section{MATERIALS AND METHODS}

The blue mussel Mytilus galloprovincialis is an organism widespread in the Mediterranean. Its biological cycle provides a good model for the analysis of differential selection on populations inhabiting a polluted environment of moderate extension such as the Lagoon of Venice. In fact, the extended larval dispersal stage (about three weeks in the related species $M$. edulis, according to Bayne, 1965) should permit the random mixing of genotypes, while the sedentary adult stage should bear the consequence of differential selection once settlement has occurred. Adult mussel samples were obtained from a number of stations in the Lagoon, forming a transect from areas of low to very high pollution.

Gene frequency analysis was carried out electrophoretically, with specific staining on a vertical slab of acrylamide gel for the products of seven enzyme loci, each of which was polymorphic with many alleles: aminopeptidase (AP), leucine aminopeptidase (LAP), phosphoglucomutase (PGM), phosphoglucose isomerase (PGI), isocitrate dehydrogenase $\left(\mathrm{IDH}_{\mathrm{s}}\right.$, soluble, and $\mathrm{IDH}_{\mathrm{m}}$ mitochondrial form), 6-phosphogluconate dehydrogenase (6-PGD). These loci were chosen on the basis of the clear and easy resolution of the allelic variants; they represent most of the genetic variation detectable in Mytilus (Rodinò, 1973; Ahmad \& Beardmore, 1976; Milkman \& Koehn, 1977; Rodinò, unpublished).

The experiments on laboratory populations were carried out using the harpacticoid copepod Tisbe holothuriae Humes, a species with a wide, almost cosmopolitan distribution and great ecological versatility.

An electrophoretic survey of 19 enzyme loci had revealed substantial genetic variability in this species (Battaglia et al., 1978a, b, 1979) and provided indications of the selective nature of at least some enzyme polymorphisms.

In order to see if, and to what extent, Tisbe populations can also be successfully utilized for experimental studies of the genetic effects of pollutants in marine organisms, the following experiments were conducted. The first pollutant tesfed was crude oil. Seawater suspensions of Kuwait oil and a solvent, Corexit 7664, were prepared and added, at various concentrations, to laboratory populations of Tisbe which were started with known initial gene frequencies for the loci PGI and AP. The initial hydrocarbon 
concentrations were analysed by gas-chromatography and spectrofluorimetric methods, which allowed determination of the stability of the suspensions with time. The stability proved reasonable from the 3rd to the 15th day after preparation (Dalla Venezia \& Fossato, 1977) at $34 \%$ salinity and ambient temperature.

The experimental and control (no oil present) populations were then sampled for electrophoretic analysis of gene frequencies every 30-40 days. Immediately after sampling, the populations were transferred to new vessels in order to reestablish the initial concentrations of the pollutant.

The experiment is still in progress. The data reported here cover a period of 300 days, corresponding to ca. 15 generations. Supplementary information on the methods adopted will be given in the section "Results" (see also Bisol et al., 1976).

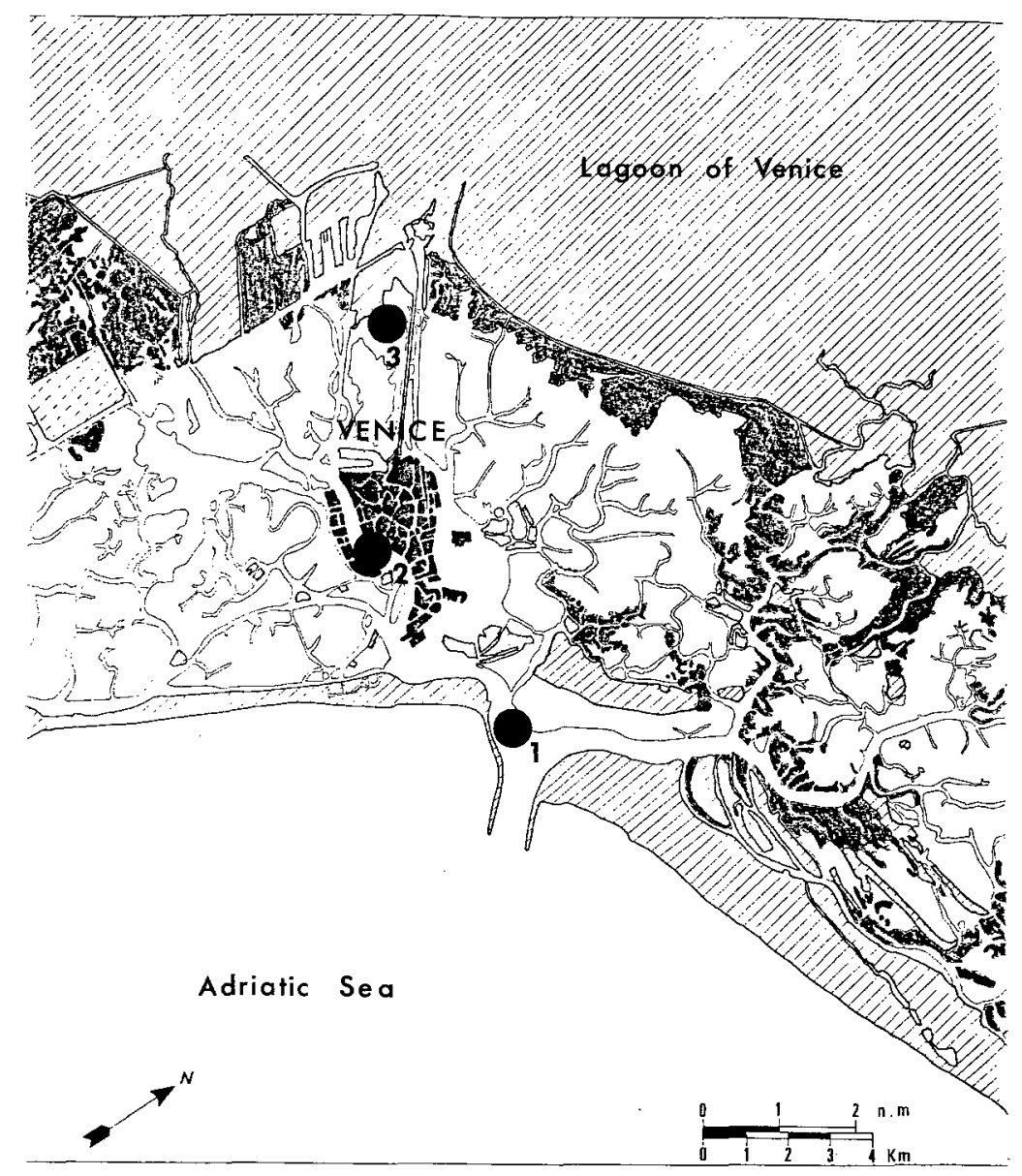

Fig. 1. Sampling stations (1979) of mussel populations in the Iagoon of Venice 


\section{RESULTS \\ Natural populations of Mytilus galloprovincialis}

Preliminary results obtained during spring 1978 (Battaglia et al., 1979) suggested that some selection was at work on the mussel population in the Lagoon of Venice. Mussel samples (each of ca. 100 adults) were then collected from seven stations situated along a gradient of pollution levels.

The analysis of the samples showed a common trend of allozyme variation along the gradient: in four out of the seven loci scored, there was a significantly higher frequency of the more common allele in the more polluted areas. A drop of the average heterozygosities correlated with the higher level of pollution. The mussel samples from the most polluted areas showed a deviation from the Hardy-Weinberg expectations, with a significant deficiency of heterozygotes.

The results presented here were obtained from samples collected during spring 1979. The experimental procedure for the analysis of the mussel population in the Lagoon of Venice was slightly modified: larger samples (ca. 200 individuals) of adult mussels were analysed, and the number of sampling stations was reduced to three. Station 1 was located in the low pollution area at the opening of the lagoon to the Adriatic Sea. Stations 2 and 3 were situated near the city basin and deep in the heavily polluted waters off the Industrial Zone, respectively (Fig. 1).

The data, including those for 1978 for comparison, are given in Tables 1 and 2.

Table 1 shows the gene frequencies of the more common allele for each of the seven loci scored in the samples. The general trend observed in 1978 seems to be confirmed: in 1979 samples there is also a higher frequency of the more common allele at six out of the seven loci. However, the frequency variations tend to be less than those of the previous

Table 1. Mytilus galloprovincialis. Frequencies of the more common allele at 7 gene loci in individuals from the Lagoon of Venice in the years 1978 and 1979. Samples were obtained from areas with different degrees of pollution

\begin{tabular}{|c|c|c|c|c|c|c|c|c|c|}
\hline \multirow{3}{*}{\multicolumn{2}{|c|}{$\begin{array}{l}\text { Areas } \\
\text { Degree of pollution } \\
\text { Year } \\
\text { Number }\end{array}$}} & \multicolumn{2}{|c|}{$\begin{array}{c}1 \\
\text { Low }\end{array}$} & \multicolumn{2}{|c|}{$\begin{array}{c}2 \\
\text { High }\end{array}$} & \multicolumn{2}{|c|}{$\begin{array}{c}3 \\
\text { Very high }\end{array}$} & \multicolumn{2}{|c|}{$P^{* *}$} \\
\hline & & 1978 & 1979 & 1978 & 1979 & 1978 & 1979 & \multirow[t]{2}{*}{1978} & \multirow[t]{2}{*}{1979} \\
\hline & & 205 & 196 & 199 & 196 & 312 & 221 & & \\
\hline Locus & \multicolumn{9}{|l|}{ Allele* } \\
\hline $\mathrm{AP}$ & 4 & .356 & .334 & .364 & .349 & .438 & .385 & $P<.01$ & n.s. \\
\hline LAP & 3 & .461 & .505 & .480 & .543 & .528 & .563 & $P<.05$ & n.s. \\
\hline 6-PGD & 3 & .937 & .916 & .948 & .936 & .941 & .966 & n.s. & $P<.05$ \\
\hline $\mathrm{IDH}$ & 5 & .488 & .487 & .497 & .538 & .559 & .548 & $P<.05$ & n.s. \\
\hline $\mathrm{IDH}_{\mathrm{s}}$ & 2 & .863 & .915 & .866 & .875 & .926 & .910 & $P<.01$ & n.s. \\
\hline $\mathrm{PGI}_{\mathrm{m}}$ & 4 & .784 & .781 & .771 & .806 & .781 & .857 & n.s. & $P<.05$ \\
\hline PGM & 4 & .459 & .521 & .510 & .526 & .511 & .569 & n.s. & n.s. \\
\hline \multicolumn{10}{|c|}{$\begin{array}{l}\text { * Alleles are numbered } 1,2,3 \ldots \text { on the basis of their relative anodic mobility } \\
\text { * The } P \text { values were computed according to a weighted homogeneity } \chi^{2} \text { test for allele } \\
\text { frequencies (Workman \& Niswander, 1970) }\end{array}$} \\
\hline
\end{tabular}


Table 2. Observed frequencies of heterozygotes $\left(H_{\mathrm{obs}}\right)$ and deviations from H.-W. expectations $(D)$ at 7 polymorphic loci in M. galloprovincialis from the Lagoon of Venice in the years 1978 and 1979.

Samples were obtained from areas with different degrees of pollution

\begin{tabular}{|c|c|c|c|c|c|c|c|c|c|c|c|c|}
\hline \multirow{4}{*}{$\begin{array}{l}\text { Areas } \\
\text { Degree of } \\
\text { pollution } \\
\text { Year } \\
\text { Number } \\
\text { Locus }\end{array}$} & \multicolumn{4}{|c|}{$\begin{array}{c}1 \\
\text { low }\end{array}$} & \multicolumn{4}{|c|}{$\begin{array}{c}2 \\
\text { high }\end{array}$} & \multicolumn{4}{|c|}{$\begin{array}{c}3 \\
\text { very high }\end{array}$} \\
\hline & \multirow{2}{*}{\multicolumn{2}{|c|}{$\begin{array}{r}1978 \\
205\end{array}$}} & \multirow{2}{*}{\multicolumn{2}{|c|}{$\begin{array}{r}1979 \\
196\end{array}$}} & \multirow{2}{*}{\multicolumn{2}{|c|}{$\begin{array}{r}1978 \\
199\end{array}$}} & \multirow{2}{*}{\multicolumn{2}{|c|}{$\begin{array}{r}1979 \\
196\end{array}$}} & \multirow{2}{*}{\multicolumn{2}{|c|}{$\begin{array}{r}1978 \\
312\end{array}$}} & \multirow{2}{*}{\multicolumn{2}{|c|}{$\begin{array}{r}1979 \\
221\end{array}$}} \\
\hline & & & & & & & & & & & & \\
\hline & $H_{\text {obs }}$ & $D$ & $H_{\text {obs }}$ & $D$ & $H_{\text {obs }}$ & $D$ & $H_{\text {obs }}$ & $D$ & $H_{\mathrm{obs}}$ & $D$ & $H_{\mathrm{obs}}$ & $D$ \\
\hline AP & .695 & -.05 & .729 & -.01 & .680 & -.07 & .740 & +.04 & .673 & -.04 & .678 & -.07 \\
\hline LAP & .515 & -.11 & .667 & +.16 & .537 & -.11 & .505 & -.12 & .474 & -.20 & .492 & -.12 \\
\hline 6-PGD & .117 & -.04 & .167 & +.07 & .090 & -.01 & .103 & -.16 & .111 & -.01 & .058 & -.10 \\
\hline $\mathrm{IDH}_{\mathrm{s}}$ & .585 & -.02 & .578 & -.07 & .567 & +.01 & .500 & -.08 & .542 & -.03 & .588 & -.00 \\
\hline $\mathrm{IDH}_{\mathrm{m}}$ & .208 & +.06 & .170 & +.10 & .244 & -.01 & .208 & -.08 & .112 & +.07 & .179 & +.09 \\
\hline PGI & .370 & +.02 & .375 & +.01 & .341 & -.10 & .302 & -.07 & .317 & -.14 & .238 & -.08 \\
\hline PGM & .631 & -.01 & .708 & +.14 & .557 & -.12 & .698 & +.11 & .581 & -.09 & .556 & -.07 \\
\hline Averages & .446 & -.03 & .485 & +.05 & .431 & $-.06^{*}$ & .445 & -.02 & .402 & $-.08^{* *}$ & .398 & $-.06^{*}$ \\
\hline
\end{tabular}

year. For only two loci (6-PGD and PGI) are they significant at the 0.05 level; both the contingency chi-square test and the weighted homogeneity test of Workman \& Niswander (1970) were used. Moreover, the variations are significant for two of the three loci which did not show important frequency changes in the previous year.

Of the four loci exhibiting variations in 1978, three also show higher frequencies of the more common allele in the more polluted area in 1979. For the PGM locus too the trend is the same, and the variation becomes significant if data for both years are pooled.

In Table 2, the deficiency of heterozygotes is expressed by the parameter $D=\left(H_{\mathrm{O}}-H_{\mathrm{E}}\right) / H_{\mathrm{E}}$, where $H_{\mathrm{O}}$ and $H_{\mathrm{E}}$ represent the respective numbers of heterozygotes observed and expected under the Hardy-Weinberg law (Koehn et al., 1976; Skibinski et al., 1978; Wilkins, 1978). Negative values of $D$ indicate a deficiency of heterozygotes, positive values an excess.

The values of $H_{\mathrm{O}}$ and $D$ for the three mussel samples undergo a gradual drop in both years, from the less to the more polluted collecting site. Average heterozygosities $\left(H_{\mathrm{obs}}\right)$ decrease and the deficiency of heterozygotes becomes significant in both years in the polluted areas. Attention may be called to the fact that this trend is not always evident if one considers single loci, but it is clearly expressed by the average values.

\section{Experimental populations of Tisbe holothuriae}

Previous research carried out on 24 experimental populations of the copepod Tisbe holothuriae with known initial gene frequencies for the locus PGI-1 had revealed the advantage of the allele $b$, compared with a and $c$, under a variety of environmental conditions. In particular, $\mathrm{b}$ is favoured by low salinities and temperatures. Equilibria are 
reached in all cases and the inferior alleles can be maintained in the population even at very low frequencies. This suggests the balanced nature of the polymorphism for the locus PGI-1.

Several experimental populations and a control one were then started; in the former crude oil was added at a concentration of $5 \mathrm{mg} / \mathrm{l}$. In all populations a significant increase in the frequency of the allele $b$ was observed. However, about three months after the beginning of the experiment (ca. 5 generations), the equilibrium frequencies in the polluted and in the control cultures were 0.80 and 0.70 , respectively. This result indicated that the presence of the pollutant might to a certain extent affect the adaptive value of the allele $b$.

To provide more information on the subject, such as the possible threshold effects of the pollutant, a new experiment was set up by employing higher concentrations of oil and considering other loci. The first available homozygous strains, cultivated in the laboratory, were the following two: PGI-1 b, AP-1 a and PGI-1 a, AP-1b; PGI-1 and AP-1 segregate independently. Each population was started with 100 females, 50 from each of the two homozygous strains. The oil concentrations in the experimental populations were 5,10 , and $18 \mathrm{mg} / \mathrm{l}$, other environmental factors being equal.

The experiment is still in proqress. So far seven samples have been taken, each consisting of 100 adults of both sexes which were individually analysed by elec-

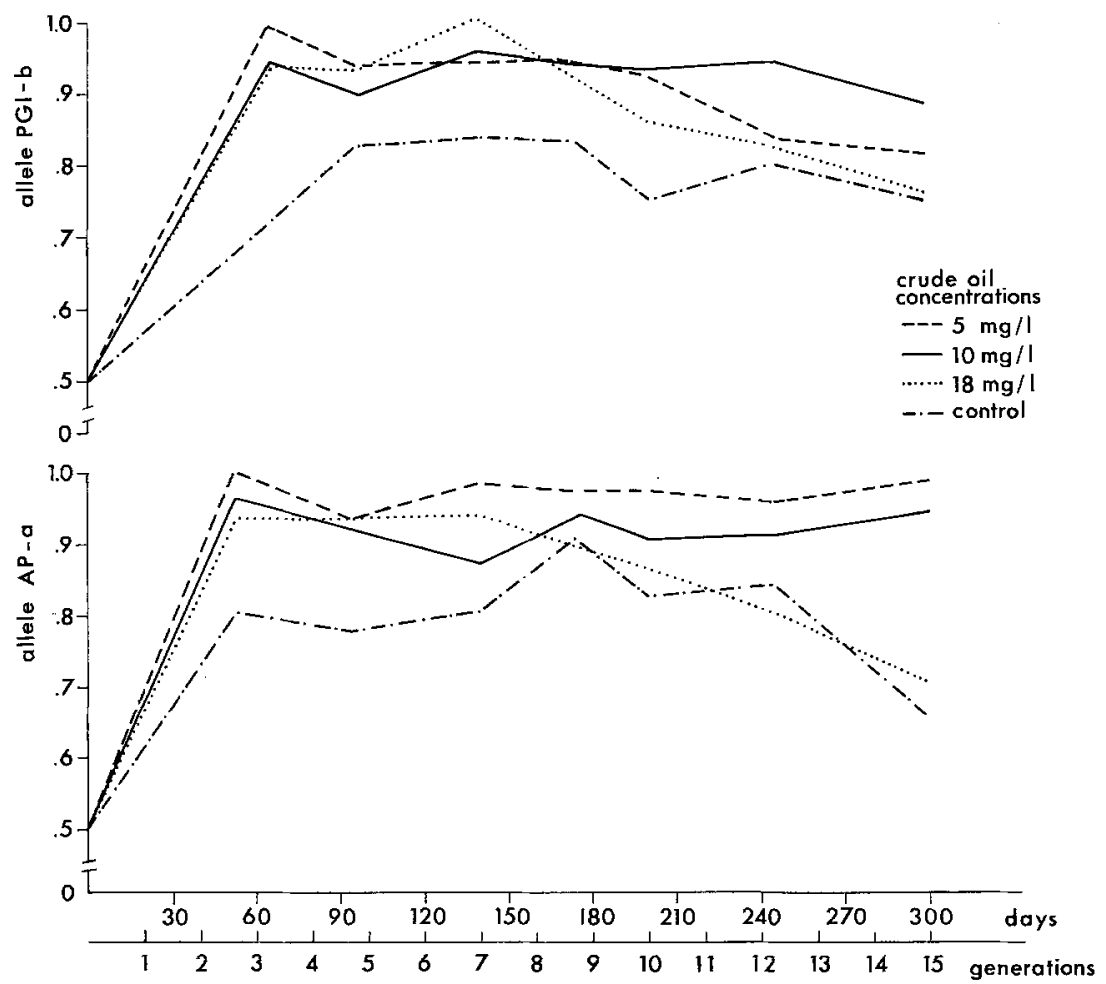

Fig. 2. Changes of gene frequencies in experimental and control populations of Tisbe holothuriae, for the loci PGI-1 and AP-1. Further explanations in the text 
trophoresis at both loci. It should be pointed out that the samples did not subtract more than a small fraction of individuals from the populations which were afterwards transferred into new vessels. The results are reported graphically in Figure 2.

Let us consider first the fate of the allele PGI-b. In the experimental populations, as well as in the control, its frequency undergoes a rapid and significant increase until equilibria seem to be attained, which occurs after about six generations. The values of $b$ are higher in the presence of the pollutant, but the difference tends to become smaller in the more recent samples. This is especially due to a drop in the frequency of $b$ in the population with the highest concentration of crude oil.

In any case, the allele PGI-b exhibits different behaviour in the polluted populations compared with the control, being significantly more favoured in the former, at least in the first half of the experiment.

The behaviour of the allele AP-a is quite similar to that of PGI-b. However, the differences between the control and the polluted populations are less significant, perhaps due to more irregular behaviour of this allele, especially from the 5 th generation onwards.

\section{DISCUSSION AND CONCLUSIONS}

Analysis of populations of the mussel Mytilus galloprovincialis for a period of two years in the Lagoon of Venice shows that at least some of the polymorphic loci detected in this species undergo significant changes in gene frequencies which can be related to the degree of pollution in the sampling areas. Moreover, lower average heterozygosities and larger deficiencies of heterozygotes were observed in the most polluted areas.

Similar results were obtained by Nevo et al. (1978) on the intertidal barnacle Balanus amphitrite. In this species the allelic frequencies at 10 of the 15 scored loci showed significant and consistent variations in consecutive years, in three localities of the bay of Haifa differing in pollution level. Besides, 9 loci out of 15 exhibited significant heterozygote deficiency, particularly at the most polluted site.

These authors expressed the hypothesis, which may also be applied to Mytilus, that natural selection is likely to favour specific alleles at each site, and that in barnacles different allozymic variants function optimally in different polluted environments. It must be pointed out, however, that the variations in allele frequencies described by Nevo et al. (1978) are much larger in absolute value than those observed in the Venice mussels. This may perhaps be related to possible differences in the biology (including reproductive behaviour and dispersal capabilities of larval stages) of the two organisms.

Heterozygote deficiencies at different loci were reported in several previous studies on related mussel species. However, most of the hypotheses which have been formulated to explain these observations (inbreeding, Wahlund effect, or presence of null alleles) do not apply to our case.

Although it may be too early to draw final conclusions about the genetic effects of pollution on Mytilus, the above results seem to indicate that the mussel population in the most polluted area is under a strong selective effect, with a well defined trend.

The results of the experiments on laboratory populations of Tisbe confirm first of all the strong selective value of the locus PGI (or of other genes closely linked with it). The fact that equilibria are reached and maintained for several generations, which was also 
observed in previous experiments (Battaglia et al., 1978b, 1979), provides further evidence of the balanced nature of this polymorphism.

The presence of oil in the water seems to affect the adaptive value of the allele PGIb. This effect is not necessarily a specific one since, as already mentioned, other environmental conditions lead to similar results. It could be argued that the presence of the pollutant creates, as with low temperatures and salinities, an unfavourable environment where the allele(s), which are more "generalist", are at a premium.

Although at the locus AP behaviour is similar to that of PGI in laboratory populations, different mechanisms may operate. In fact, (1) no other data are available indicating the selective advantage of the allele AP-a; (2) in the strain employed for starting the laboratory populations AP-a was together with PGI-b the superior allele at that locus. Therefore, considering the way the populations were set up, it cannot be excluded that the advantage of AP-a is only apparent, largely depending on the higher fitness of PGI-b, with which the former remains in association for some time. Preliminary data suggest that the homozygotes for the allele PGI-b develop faster than homozygotes for other alleles, which might account for the higher frequency, at least during the initial generations, of individuals PGI-b, AP-a.

An interpretation of the peculiar behaviour of the alleles PGI-b and AP-a in the most polluted populations would be premature. Further experiments are required to clarify this point.

The observations and experiments described in the present paper represent an initial attempt to show the possible selective action of certain pollutants in the marine habitat, and to make clear the mechanisms involved. The organisms employed, particularly Tisbe, seem to be promising material for an experimental approach to the problem of the genetic effects of pollution in the sea.

One suggestive feature of the data on mussel populations is the decrease of heterozygosity in polluted areas. It would be of interest both from the theoretical and from the practical point of view to extend these observations to other marine organisms suffering stress from pollution or other environmental factors. These findings, if confirmed by further research, might also have some predictive value in monitoring pollution in the marine habitat.

Acknowledgements. This research was supported by the Italian National Research Council (P. F. "Environment"). The authors wish to express their gratitude to Dr. V. U. Fossato for his help in the chemical analysis of pollutants.

\section{LITERATURE CITED}

Ahmad, M. \& Beardmore, J. A., 1976. Genetic evidence that the "Padstow mussel" is Mytilus galloprovincialis. - Mar. Biol. 35, 139-147.

Battaglia, B., Bisol, P. M. \& Fava, G., 1978a. Genetic variability in relation to the environment in some marine invertebrates. In: Marine organisms. Ed. by B. Battaglia \& J. A. Beardmore. Plenum Press, New York, 53-70.

Battaglia, B., Bisol, P. M. \& Varotto, V., 1978b. Variabilité génétique dans des populations de Tisbe holothuriae (Copepoda, Harpacticoida) marine et d'eau saumâtre. - Archs Zool. exp. gén. 119, 251-264. 
Battaglia, B., Bisol, P. M., Fossato, V. U. \& Rodinò, E., 1979. Studies on the genetic effects of pollution in the sea. ICES Workshop on monitoring of biological effects of pollution in the sea. (In press.)

Bayne, B. L., 1965. Growth and the delay of metamorphosis of the larvae of Mytilus edulis (L.). Ophelia 2,1-47.

Bisol, P. M., Varotto, V. \& Battaglia, B., 1976. Controllo genetico della fosfoesosoisomerasi (Phi) in Tisbe clodiensis (Copepoda, Harpacticoida). - Atti Accad. naz. Lincei, Rc. (Cl. Sci. Fis. mat. nat.) $60,499-504$.

Dalla Venezia, L., \& Fossato, V. U., 1977. Characteristics of suspension of Kuwait oil and Corexit 7664 and their short- and long-term effects on Tisbe bulbisetosa (Copepoda, Harpacticoida). Mar. Biol. 42, 233-237.

Fossato, V. U. \& Siviero, E., 1974. Oil pollution monitoring in the Lagoon of Venice using the mussel Mytilus galloprovincialis. - Mar. Biol. 25, 1-6.

Koehn, R. W., Milkman, R. \& Mitton, J. B., 1976. Population genetics of marine pelecypods. IV. Selection, migration and genetic differentiation in the blue mussel Mytilus edulis. - Evolution 30, 2-32.

Milkman, R. \& Koehn, R. W., 1977. Temporal variation in the relationship between size, numbers, and allele-frequency in a population of Mytilus edulis. - Evolution 31, 103-115.

Nevo, E., Shimony, T. \& Libni, M., 1978. Pollution selection of allozyme polymorphism in barnacles. - Experientia 34, 1562-1564.

Rodinò, E., 1973. Polimorfismo della LAP (Leucina-Amino-Peptidasi) in Mytilus galloprovincialis della Laguna di Venezia. - Atti Congr. Soc. it. Biol. mar. 5, 179-180.

Ruivo, M. (Ed.), 1972. Marine pollution and sea life. Fishing News Books, London, $624 \mathrm{pp}$.

Skibinski, D. O. F., McNee, A. R. \& Beardmore, J. A., 1978. Protein variation in the marine bivalve Scrobicularia plana. - Anim. Blood Groups biochem. Genet. 9, 223-228.

Wilkins, N. P., 1978. Length-correlated changes in heterozygosity at an enzyme locus in the scallop (Pecten maximus). - Anim. Blood Groups biochem. Genet. 9, 69-77.

Workman, P. L. \& Niswander, J. D., 1970. Population studies in southwestern Indian tribes. II. Local genetic differentiation in the papago. - Am. J. hum. Genet. 22, 24-49. 